\title{
Aplicação de Caminhamento Elétrico para caracterização geológico -geotécnica de área potencialmente cárstica em Cajamar (SP)
}

\author{
Flávio Anauate Bergonzoni, graduando em Geologia, IGCE-Unesp
}

Malena D'Elia Otero - Geóloga. Mestranda do Programa de Pós-Graduação em Geociências (IG-UNICAMP); Reconverte Planejamento e Projetos

José Antonio Gonçalves - Engenheiro Geólogo; Reconverte

Planejamento e Projetos

Copyright 2018, SBGf - Sociedade Brasileira de Geofísica

Este texto foi preparado para a apresentação no VIII Simpósio Brasileiro de Geofísica, Salinópolis, 18 a 20 de setembro de 2018. Seu conteúdo foi revisado pelo Comité Técnico do VIII SimBGf, mas não necessariamente representa a opinião da SBGf ou de seus associados. É proibida a reprodução total ou parcial deste material para propósitos comerciais sem prévia autorização da SBGf.

\section{Resumo}

The present paper presents the results of a $2 \mathrm{D}$ Eletric Imaging method executed in an area where a real estate development will take place. The area is located in Cajamar city, São Paulo and constitutes karstic terrain which is subject to the occurrence of groundwater, dolines, soil colapses, processes that must be taken in consideration before executing any engineering project. Therefore we have a geological setting fit for the use 2D Eletric Imaging method which is efficient in detecting groundwater, dissolution features, and other underground structures.

\section{Introdução}

A ocorrência de abatimentos de solo em Cajamar - SP no ano de 1986 deixou evidente que são necessários estudos mais aprofundados acerca de feições de dissolução e cavidades subterrâneas na região. Em terrenos cársticos sujeitos a expansão urbana como é o caso sugere-se o uso de métodos de investigação indiretos como a geofísica para a possível detecção de espaços vazios e prevenção de acidentes e abatimentos de solo. O presente estudo aborda a utilização do método da eletrorresistividade para a detecção de possíveis vazios estruturais em uma área cárstica aonde será realizado um empreendimento imobiliário. A área de estudo se localiza na cidade de Cajamar- SP no bairro Guaturinho (figura 1), microrregião de Osasco distante 29 quilômetros da capital paulista.

Os resultados do ensaio serão usados para guiar a campanha de investigação direta, que será realizada através de um roteiro de sondagem mista: SPT no trecho de solo e rotativa em rocha. Os resultados dos métodos diretos irão posteriormente ser comparados e integrados aos resultados dos métodos indiretos, proporcionando um estudo completo acerca da aplicação do método do Imageamento Elétrico e das resistividades das rochas presentes na região.

A geologia da região situada na Província Mantiqueira é aquela correspondente do Grupo São Roque na Faixa Jaraguá Cristais (CARNEIRO, 1983) aonde encontramos intercalações de metapelitos com carbonatos e intrusões granitoides diversas. Em um estudo preliminar de campo

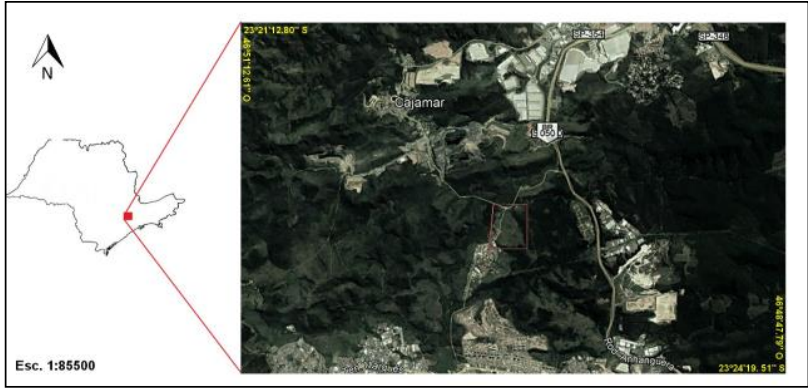

Figura 1: Mapa de localização da área de Estudo

foram reconhecidos mica-xistos com foliações dobradas (figura 2) e clivagem de crenulação. As foliações identificadas em campo correspondem àquelas descritas por Carneiro (1983) e Menegasse (1991).

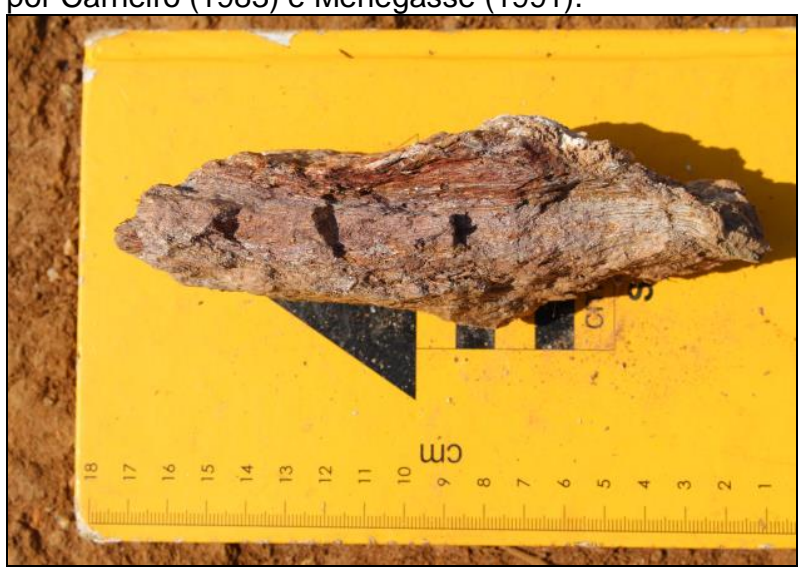

Figura 2: Mica-xisto apresentando clivagem de crenulação

\section{Metodologia/ Problema Investigado}

Neste trabalho foi realizada a técnica do Imageamento Elétrico com o arranjo Dipolo-Dipolo (D-D). O arranjo D-D é descrito por Gandolfo (2007) como o arranjo mais difundido dentre os existentes com amplas utilizações nas áreas de mineração, prospecção de água subterrânea, estudos ambientais e geologia de engenharia. $O$ ensaio realizado em campo através do método Dipolo-Dipolo é executado através de uma série de medidas aonde se mantém fixo tanto o espaçamento dos dipolos de emissão (AB) quanto os de recepção (MN) e a medida que eles são separados de acordo com um fator "n.a" temos diferentes níveis de investigação em profundidade (GANDOLFO et al, 2007). Durante a realização do caminhamento o arranjo é deslocado na mesma distância entre a separação dos eletrodos $(a=20)$ e repetindo-se esse procedimento temos a construção de 
uma pseudo-seção de resistividade elétrica aparente ao longo da linha do caminhamento.

Os dados foram adquiridos ao longo de seis linhas de caminhamento totalizando um total de 3.300 metros com espaçamento entre os eletrodos de $20 \mathrm{~m}$ (figura 3 ). Sendo assim espera-se uma profundidade investigada de $\mathrm{R}=120 \mathrm{~m}$. As seis linhas foram posicionadas ao longo do terreno investigado a fim de se identificar possíveis cavidades, água subterrânea, contatos litológicos, falhas e outras descontinuidades de maneira que sejam obtidas informações para direcionar de forma otimizada a campanha de ensaios diretos.

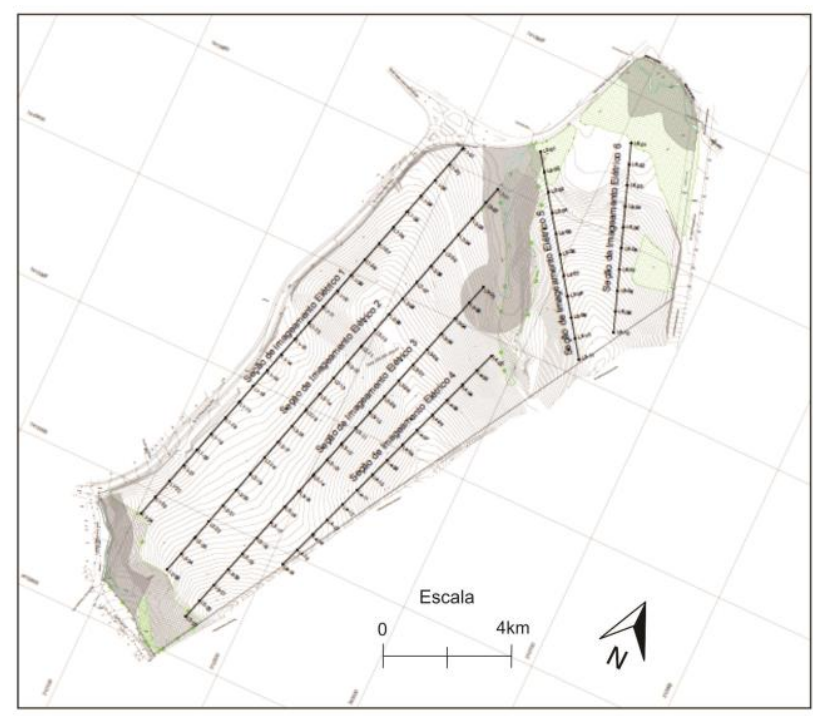

Figura 3: Arranjo das seis linhas dispostas na área de estudo com espaçamento de eletrodos $n=20 m$

O equipamento utilizado foi eletrorresistivímetro digital modelo SAS-1000 fabricado pela ABEM - AB da Suécia versão 2014 além de eletrodos de aço inoxidável com $40 \mathrm{~cm}$ de comprimento e $20 \mathrm{~mm}$ de diâmetro, bateria de $12 \mathrm{~V}$ comum e conjunto de cabos condutores de diferentes cores que conduzem as correntes elétricas induzidas nos eletrodos de corrente e gerada nos eletrodos de potencial (figura 4).

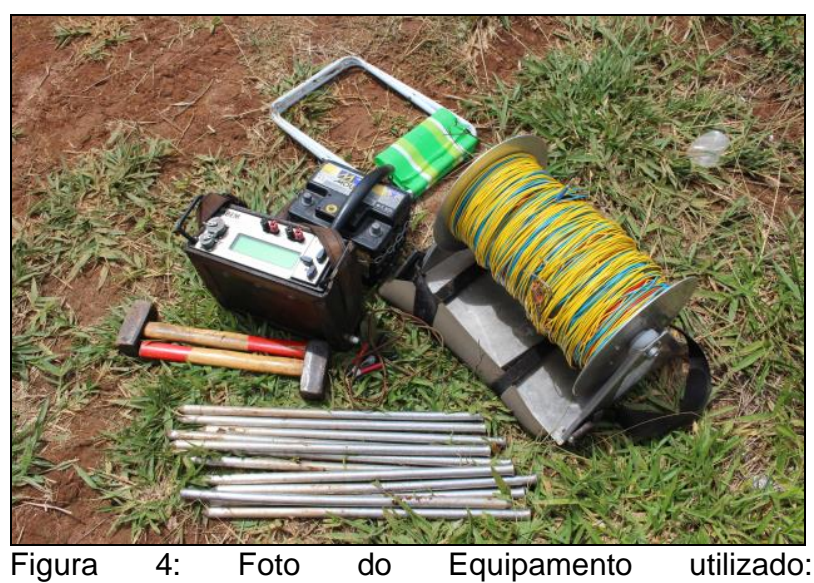

Eletrorresistivímetro SAS-1000, eletrodos de aço inoxidável, bobina de cabos condutores, bateria de $12 \mathrm{~V}$, marretas.

Os dados obtidos de resistividade foram processados através do software Res2lnv que faz a inversão dos dados para gerar perfis de imageamento elétrico em duas dimensões. A inversão é feita a partir da geração de pseudo-seções de resistividade aparente. A medida aparente é expressa em ohm.m da mesma maneira que a resistividade real e como em situações reais temos alta heterogeneidade do meio natural e variações tanto laterais quanto de profundidade, os valores medidos irão variar para cada posição e arranjo / disposição de eletrodos utilizado (GANDOLFO, 2007). Em casos de ambientes mais homogêneos como camadas estratificadas as pseudo-seções possibilitam boas análises qualitativas. O software de inversão faz uma série de interações a partir da pseudo-seção aparente medida de forma a buscar um modelo matemático de parâmetros físicos que mais se aproxima ao modelo gerado a partir dos dados obtidos em campo. Sendo assim após a inversão temos uma pseudo-seção de resistividade aparente calculada e um modelo geoelétrico conhecido a partir do qual é elaborada a seção de resistividade final. Estima-se que os resultados dos ensaios estejam bons quando as pseudo-seções de resistividade aparente medida se assemelham às pseudo-seções de resistividade aparente calculada, situação que foi comprovada durante o processo de inversão dos dados do ensaio.

\section{Resultados}

As seções são apresentadas em termos de distância versus profundidade, em uma escala cromática. Os dados de background usados para os estudos nessa região foram uma faixa de $20 \Omega$.m até $10.000 \Omega$.m. Nas seções as cores quentes representam valores de resistividades mais altos enquanto as cores frias estão associadas a resistividades baixas.

Sendo assim observamos ao longo das seções 1 e 2 a

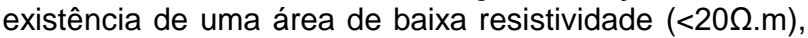
com expressiva predominância lateral em profundidades de cerca de 60 metros (figura 5). Já nas seções 5 e 6 realizadas na porção NE do terreno (figura 7) temos a presença de áreas com resistividade altas, maiores que $10.000 \Omega$. m a partir de profundidades de $40 \mathrm{~m}$ até $90 \mathrm{~m}$. Essas anomalias resistivas aparentemente tem continuidade além do nível de investigação preterido pelos ensaios. Também foram observadas anomalias resistivas em profundidades menores de $30 \mathrm{~m}$ a $50 \mathrm{~m}$ como observamos nas seções 2 e 3 (figura 6).

A figura 5 mostra um mapa em planta com as resistividades para uma profundidade de $90 \mathrm{~m}$, nível aonde se encontram a maioria das anomalias medidas no caminhamento elétrico. Sendo assim os ensaios de eletrorresistividade indicaram a existência de 2 zonas anômalas nas duas diferentes porções do terreno: Temos anomalias condutivas de expressão lateral na porção Centro-Sul da área aonde foram realizadas as linhas de caminhamento $1,2,3$ e 4 e anomalias extremamente 
resistivas na porção NW aonde foram realizadas as linhas de caminhamento 5 e 6.

Considerando-se os dados obtidos em campo e a geologia da região de estudo que configura um já reconhecido relevo cárstico, as anomalias encontradas durante os ensaios podem ter diferentes interpretações. A anomalia condutiva com certa expressão lateral de direção N-S que observamos ao longo das linhas 2 e 3 pode representar possíveis cavidades preenchidas com água a uma profundidade de 60 metros. Já as anomalias altamente resistivas localizadas nas linhas 5 e 6 se encontram em profundidades de $60 \mathrm{~m}$ em diante e podem representar cavidades vazias ou diferentes tipos litológicos. O contexto regional da área indica que existem rochas intercaladas com os pacotes metapelíticos como quartzitos e anfibolitos metabasíticos (SANTORO et al, 1988) que teriam resistividades altas e poderiam corresponder a essas anomalias.

\section{Discussão e Conclusões (Arial Bold, 9)}

Os eventos de abatimento de solo e dolinas levaram a importantes estudos do Instituto de Pesquisa Tecnológica (IPT) na década de 80 que indicaram a existência de um nível carbonático na região de Cajamar em que se desenvolvem processos de dissolução cársticos (SANTORO et al, 1988). Sendo assim o reconhecimento prévio de campo aliado ao trabalho de revisão bibliográfica foram essenciais para a escolha da realização do caminhamento elétrico na investigação da área, método eficiente para a detecção de cavidades vazias e processos de dissolução em terrenos cársticos (GANDOLFO, 2007). A existência dessas cavidades e possivelmente de água em subsuperfície no terreno aonde será construído o empreendimento são informações necessárias para evitar acidentes e abatimentos de solo. Sendo assim sugere-se a investigação direta em pelo menos dois pontos da área: o primeiro ao longo da anomalia condutora entre as seções 1 e 2 que pode representar um bolsão de água a 60 metros de profundidade; e o segundo nas anomalias resistivas ao longo das seções 5 e 6 que podem indicar possíveis cavidades subterrâneas.

Podemos concluir que a aplicação do caminhamento elétrico na investigação geológica-geotécnica do terreno foi adequada indicando possíveis locais para os ensaios de investigação direta, que podem reduzir os custos do projeto e os riscos para a implantação do empreendimento imobiliário.

\section{Agradecimentos}

Os autores agradecem a todos envolvidos no projeto pela possibilidade de realizar o ensaio e pela participação no projeto de investigação geológica da área.

\section{Referências}

CARNEIRO, C. D. Análise estrutural do Grupo São Roque na faixa entre o pico do Jaraguá e a Serra dos
Cristais. 1983. Tese de Doutorado. Tese de doutorado, Instituto de Geociências, Universidade de São Paulo, São Paulo.

GANDOLFO, O. C. B. Um estudo do imageamento geoelétrico na investigação rasa. 2007. Tese de Doutorado. Universidade de São Paulo.

MENEGASSE, L. N. Estudo hidrogeológico das rochas metassedimentares do Grupo São Roque a NW da grande São Paulo: critérios para a locação de poços profundos. 1991. Tese de Doutorado. Universidade de São Paulo.

SANTORO, E. et al. Estrutura geológica da região de Cajamar-Jordanésia, SP. Revista Brasileira de Geociências, v. 18, n. 3, p. 353-361, 1988 

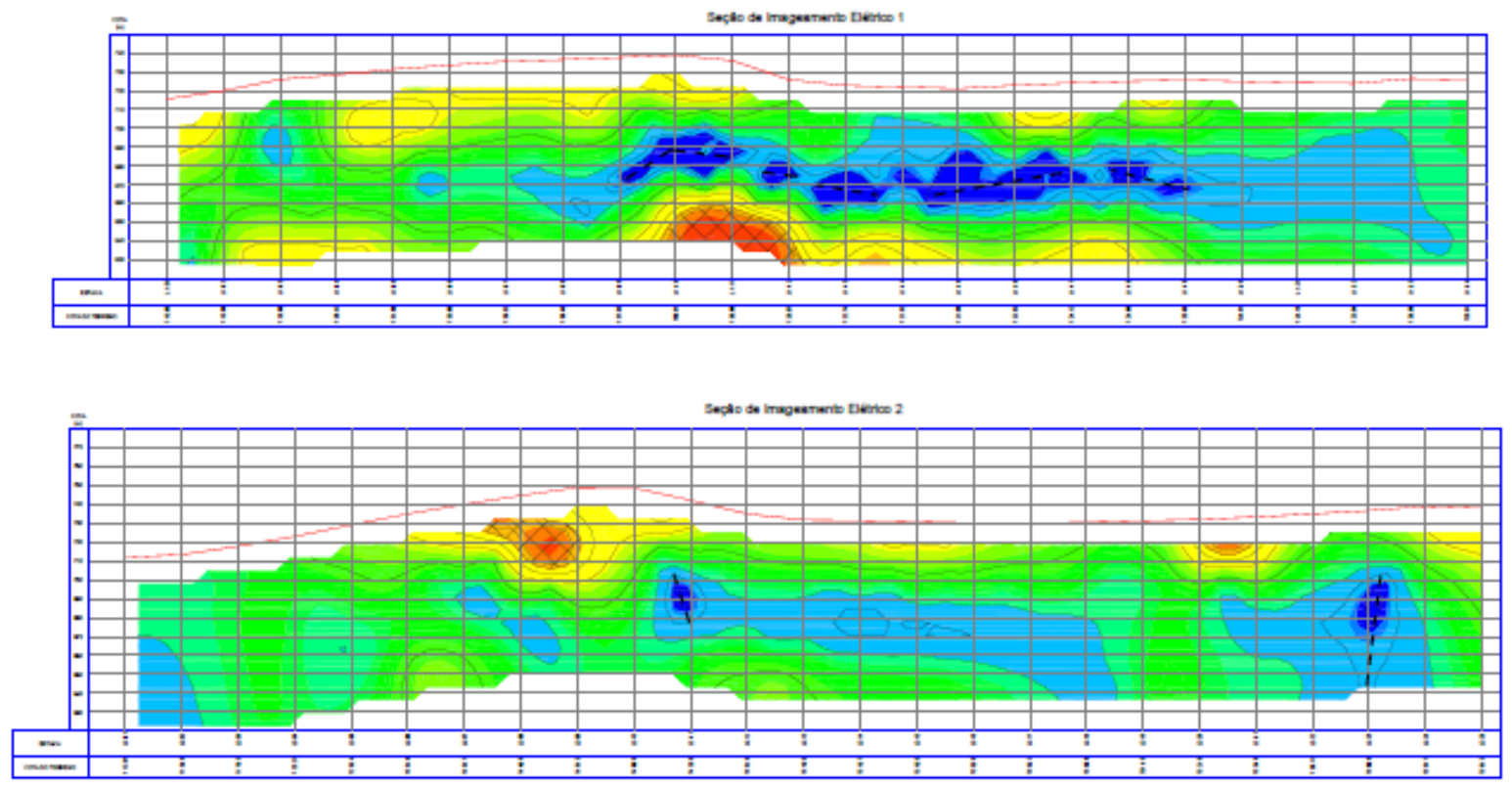

Figura 5: Modelos de inversão para as linhas 1 e 2
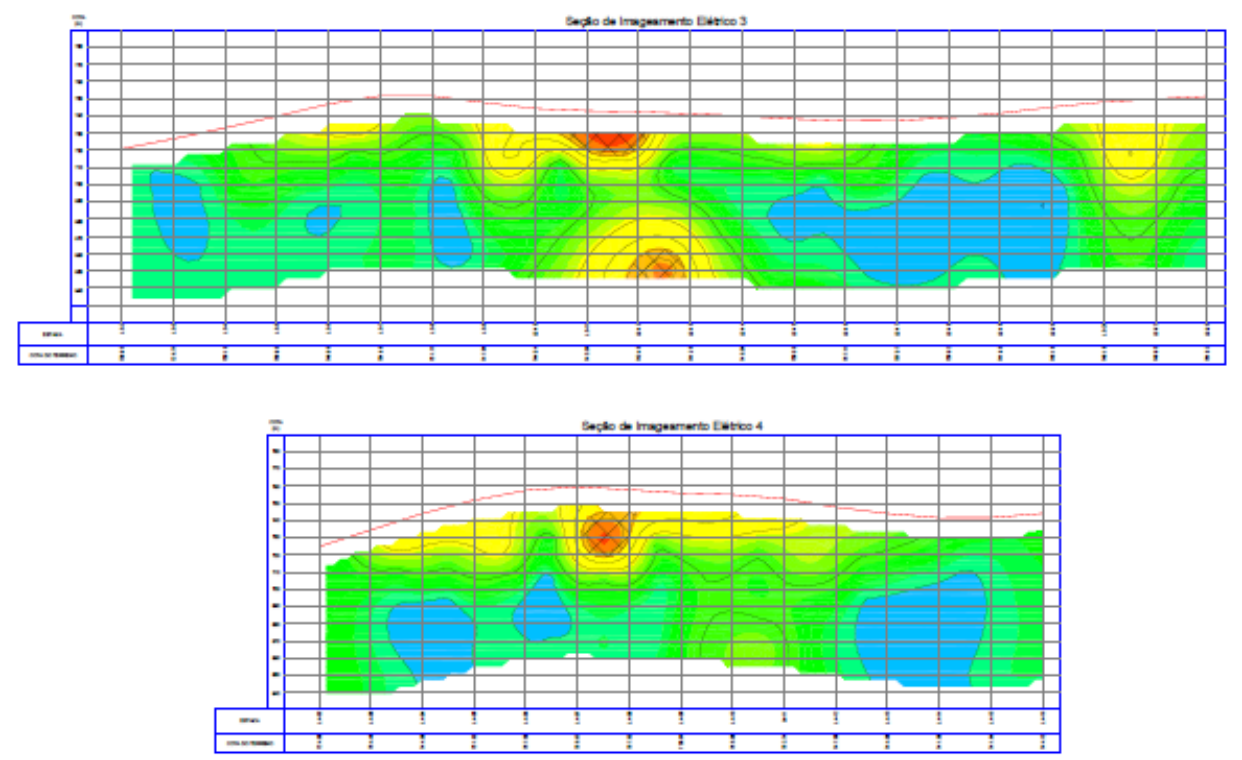

Figura 6: Modelos de inversão para as linhas 3 e 4 

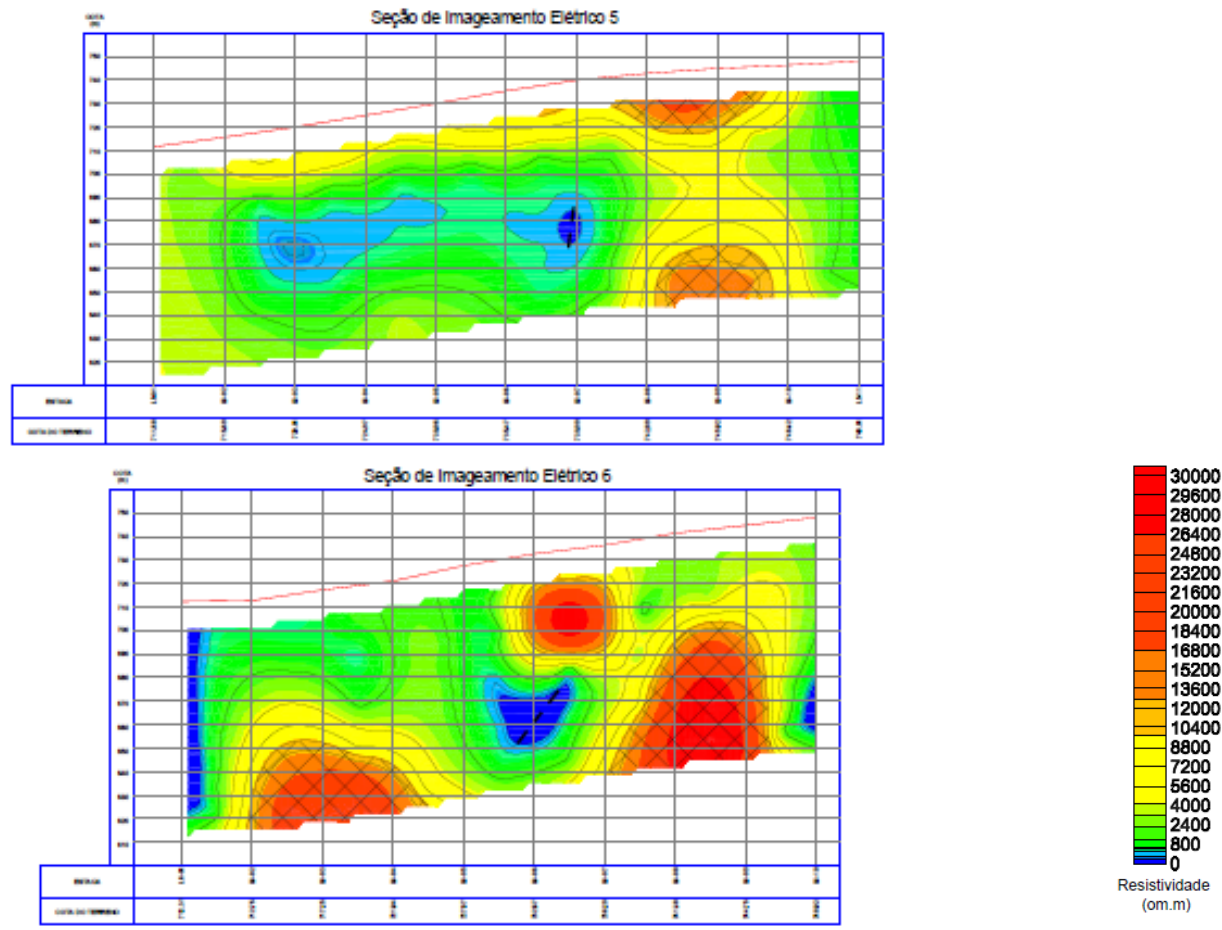

Figura 7: Modelos de inversão para as linhas 5 e 6

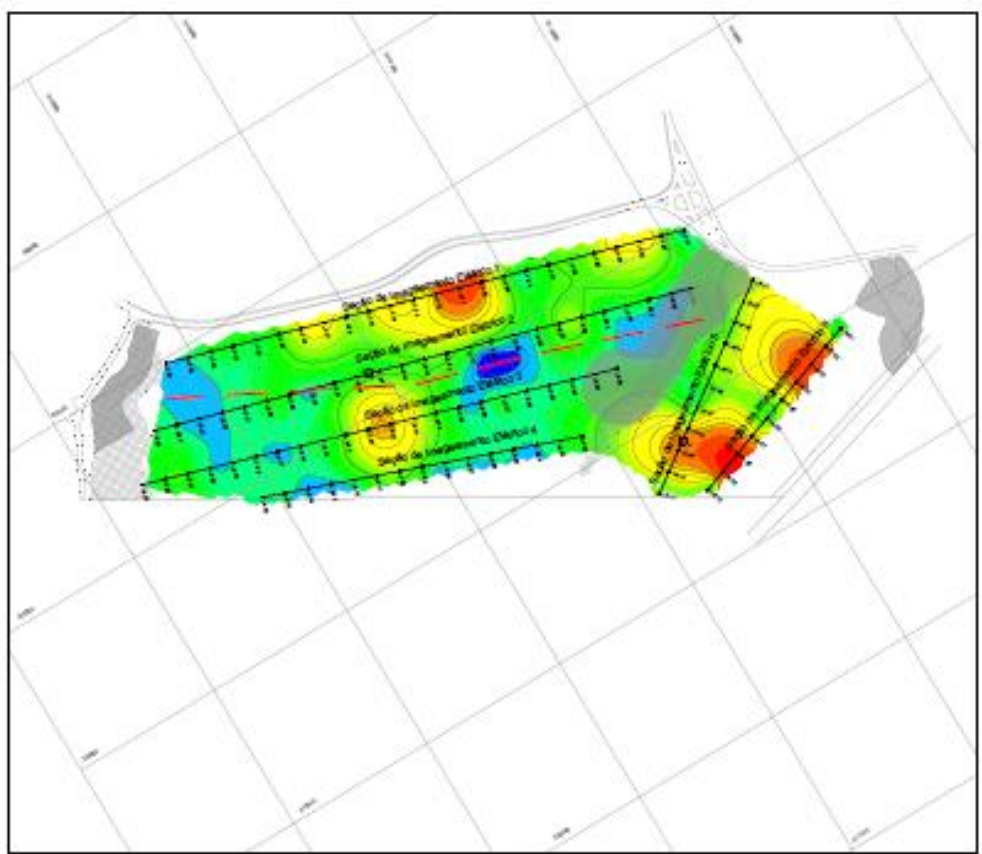

Figura 8: Mapa de resistividades Para uma profundidade de 60 metros 